\title{
Analysis on the Changes and its Influencing Factors of College Students' Physical Health in Dalian
}

\author{
Yang Zhang \\ Department of Physical Education \\ Dalian Neusoft University of Information \\ Dalian City, China, 116032
}

\begin{abstract}
College students are the backbone force of China's future socialist construction. Talents in institutions of high learning influence the construction and development of our country in the future. Their physical condition directly affects the whole people's physical health level as well as China's future development and the rise and fall of the nation [2]. This study randomly selects 399 college students in Dalian as the research object to track and investigate the factors to change their physical health in four years in university through the methods of questionnaire and follow-up survey and on the basis of the test data of items such as height, weight, lung capacity, 50 meters dash in Student Physical Health Standard jointly formulated by the Ministry of Education and General Administration of Sports. The result shows that students' physical health has been declining since their freshman year. The main reasons for the change of their physical health lie in the bad habits of surfing the Internet, lack of awareness of exercise and bad living habits.
\end{abstract}

Keywords-college students, physical health, influencing factors, Analysis

\section{INTRODUCTION}

\section{A. Topic basis}

Nowadays, college students are an important part of national youth population, and their physical health condition will, to a large extent, affect the youth population, even the national physical condition [1]. In addition to solid professional knowledge and skills, qualified talents cultivated by universities must also have a healthy body, because good physical condition and health level are the prerequisite for them to healthily work for the national for 50 years. However, the current physical condition of college students in China is not very optimistic. They enjoy the achievements of scientific and technological development at the price of physical function degradation [5]. Deng Xiaoping once told us to be good at discovering new problems and studying new situations. When facing such a problem, both educators and the educated should have a comprehensive understanding on it and find out the factors affecting students' physical health, which is the necessity and basis to research this issue.

\section{B. Research significance and purpose}

College students account for a large proportion in the national youth population, and their physical conditions will largely affect the physical health of young people, even the whole nation. In recent years, the physical quality of college students in China has decreased significantly, which has attracted the attention of all sectors of society. Therefore, it is necessary to make a comprehensive investigation and understanding of the physical health status of college students, explore its influencing factors and put forward corresponding improvement measures.

\section{RESEARCH METHOD}

\section{A. Questionnaire approach}

1) The design, reliability and validity test of questionnaire.

The "Questionnaire on College Students' Life Habits" is finally designed in accordance with actual situation by asking for advice from multiple experts and referring to the questionnaire form of relevant studies. Logical analysis is used to test the validity of the questionnaire. 22 relevant experts (including 16 professors and 6 associate professors) are invited to review the content of the questionnaire and conduct logical and effective analysis. The validity test results are shown in the table. In terms of structural validity, the proportion of experts choosing feasibility and basic feasibility is $90.9 \%$, and the proportion of experts choosing feasibility and basic feasibility is $95.4 \%$ in terms of content validity. Retest method is used to test its reliability, that is, 67 students are selected who are given the same questionnaire after 15 days. The final reliability coefficient is $r=0.81 \quad(\mathrm{P}<0.05)$. Therefore, the validity and reliability of the questionnaire meet the requirements of the survey.

\section{2) Questionnaire distribution and collection}

A total of 421 questionnaires were distributed and 407 were collected, among which 399 were valid. The rate of collection and validity are $96.7 \%$ and $94.8 \%$ respectively. Students were asked to fill in the questionnaire on the spot to ensure the collection and the quality of the questionnaire. Finally, 399 valid questionnaires were confirmed. 


\section{B. Follow-up survey}

College students are selected as the subject of research. Their life habits and physical condition in the past four years were investigated.

\section{Mathematical statistics}

SPSS18.0 statistical software is used to conduct mathematical statistics on the physical health indicators of the subjects in the four years, and $\mathrm{T}$ test is used for various indicators of the control group and the normal group in order to discuss the influence of network, exercise awareness and bad habits on the physical health of college students.

\section{RESUlT AND ANALYSIS}

\section{A. The change of college students' body}

Body shape is an explicit indicator of growth and development. The following tables show the body shape changes in two different periods.

TABLE I. THE CHANGE OF HEIGHT

\begin{tabular}{|c|c|c|c|c|c|}
\hline Grade & $\mathrm{n}$ & $\mathrm{M} \pm \mathrm{SD}(\mathrm{cm})$ & Difference Value $(\mathrm{cm})$ & $\mathrm{t}$ & $\mathrm{P}$ \\
\hline Freshman & 399 & $174.83 \pm 6.19$ & -1.86 & -12.96 & $<0.01$ \\
\hline Senior & 399 & $176.69 \pm 5.98$ & & & \\
\hline
\end{tabular}

Height is an important indicator of body shape. As shown in table 1, after entering the university, the physical development continues and the height also increases year by year, with an average increase of about $2 \mathrm{~cm}$.

TABLE II. THE CHANGE OF WEIGHT

\begin{tabular}{|c|c|c|c|c|c|}
\hline Grade & $\mathrm{n}$ & $\mathrm{M} \pm \mathrm{SD}(\mathrm{kg})$ & Difference Value $(\mathrm{kg})$ & $\mathrm{t}$ & $\mathrm{P}$ \\
\hline Freshman & 399 & $72.15 \pm 14.75$ & 2.15 & 5.61 & $<0.01$ \\
\hline Senior & 399 & $70.00 \pm 12.77$ & & & \\
\hline
\end{tabular}

Weight index is an important index to evaluate nutritional status and body symmetry. As shown in table 2, the weight in the two periods decreases with a decrease of about $2 \mathrm{~kg}$. College life is not only a critical period of learning, but also an important period of growth and development.

TABLE III. THE CHANGE OF OBESITY (BMI)

\begin{tabular}{|c|c|c|c|c|c|}
\hline Grade & $\mathrm{n}$ & $\mathrm{M} \pm \mathrm{SD}$ & Difference Value & $\mathrm{t}$ & $\mathrm{P}$ \\
\hline Freshman & 399 & $23.56 \pm 4.43$ & 1.12 & 7.47 & $<0.01$ \\
\hline Senior & 399 & $22.44 \pm 3.92$ & & & \\
\hline
\end{tabular}

BMI (body mass index, also known Quetelet index) is the square number that comes with the kilogram number of weight divide the meter number of height, which is an international standard that measures fat degree and healthy of human body.

Chinese physical quality index: light weight: $\mathrm{BMI}<18.5$, healthy weight: $18.5<=\mathrm{BMI}<24$, overweight: $24<=$ BMI $<28$, obesity: $28<=$ BMI

As shown in Table 3, BMI index in two periods are within the normal range with the difference of index of about 1 , having no significant changes.

\section{B. The change of bodily function}

Bodily function refers to the life activities of the whole human body and its constituent organs and systems.

TABLE IV. THE CHANGE OF LUNG'S CAPACITY

\begin{tabular}{|l|c|c|c|c|c|}
\hline \multicolumn{1}{|c|}{ Grade } & $\mathrm{n}$ & $\mathrm{M} \pm \mathrm{SD}(\mathrm{mL})$ & $\begin{array}{c}\text { Difference } \\
\text { Value }(\mathrm{mL})\end{array}$ & $\mathrm{t}$ & $\mathrm{p}$ \\
\hline Freshman & 399 & $3959.71 \pm 694.88$ & 195.9 & 4.84 & $<0.01$ \\
\hline Senior & 399 & $3763.81 \pm 755.36$ & & & \\
\hline
\end{tabular}

As shown in table 4 , in terms of lung capacity in the two periods, lung capacity in the fourth year decreases compared with the first year, but not so obvious.

\section{The change of physical quality}

Physical quality usually refers to the basic ability of human muscle activity, which is the comprehensive reflection of the functions of the human organs system in the muscle work.

TABLE V. THE CHANGE OF SPEED QUALITY (50-METER DASH)

\begin{tabular}{|c|c|c|c|c|c|}
\hline Grade & $\mathrm{n}$ & $\mathrm{M} \pm \mathrm{SD}(\mathrm{s})$ & Difference Value(s) & $\mathrm{t}$ & $\mathrm{p}$ \\
\hline Freshman & 399 & $7.27 \pm 0.58$ & -1.21 & -29.37 & $<0.01$ \\
\hline Senior & 399 & $8.48 \pm .54$ & & & \\
\hline
\end{tabular}

50-meter dash is the common project to test students' explosive force. As shown in table 5, the result in the fourth year significantly decreases compared with the first year.

TABLE VI. THE CHANGE OF ENDURANCE (1000-METER RUNNING)

\begin{tabular}{|c|c|c|c|c|c|}
\hline Grade & $\mathrm{n}$ & $\mathrm{M} \pm \mathrm{SD}(\mathrm{s})$ & Difference Value(s) & $\mathrm{t}$ & $\mathrm{p}$ \\
\hline Freshman & 399 & $249.66 \pm 19.85$ & -34.68 & -30.29 & $<0.01$ \\
\hline Senior & 399 & $284.34 \pm 11.05$ & & & \\
\hline
\end{tabular}

College students are in the critical period of increasing their endurance and lung capacity. Due to the monotony and particularity of the project itself, students are often in a passive situation when exercising. As shown in table 6, the result of the senior students significantly decreases compared with that of freshmen.

TABLE VII. THE CHANGE OF STRENGTH QUALITY (STANDING LONG JUMP)

\begin{tabular}{|c|c|c|c|c|c|}
\hline Grade & $\mathrm{n}$ & $\mathrm{M} \pm \mathrm{SD}(\mathrm{m})$ & Difference Value $(\mathrm{m})$ & $\mathrm{t}$ & $\mathrm{p}$ \\
\hline Freshman & 399 & $2.69 \pm 0.19$ & -0.36 & 26.51 & $<0.01$ \\
\hline Senior & 399 & $2.33 \pm 0.18$ & & & \\
\hline
\end{tabular}

Standing long jump is an important item to test jumping power, which is closely related to muscle type and explosive force. As shown in table 7 , the result in the fourth year decreases compared with the first year, but not so obvious.

\section{Analysis on the factors to influence students' physical health}

There are a variety of factors affecting students' physical health. The factors affecting students' physical health are found out through questionnaires. 
According to the Internet report released by China Internet Network Information Center, the total number of Internet users in mainland China has reached 510 million, among which students account for the highest proportion, reaching about $32.3 \%$ in the total number of Internet users. And college students occupy a large proportion among students Internet users. Against the background of the rapid development of the Internet, due to a variety of reasons, college students' awareness of physical exercise is weak. The "phubbers" that can be seen everywhere have become a "different landscape" on the campus [4].

TABLE VIII. SURVEY ON THE ONLINE TIME (EVERYDAY)

\begin{tabular}{|c|c|c|c|c|c|c|c|}
\hline Index & $\begin{array}{c}\text { Within an } \\
\text { hour }\end{array}$ & $\begin{array}{c}\text { Within } 1 \text { hour and } 2 \\
\text { hours }\end{array}$ & $\begin{array}{c}\text { Within } 2 \text { hour and } 3 \\
\text { hours }\end{array}$ & $\begin{array}{c}\text { Within } 3 \text { hour and } 4 \\
\text { hours }\end{array}$ & $\begin{array}{c}\text { Within } 4 \text { hour and } 6 \\
\text { hours }\end{array}$ & $\begin{array}{c}\text { Above } 6 \\
\text { hours }\end{array}$ & Total \\
\hline $\begin{array}{c}\text { Number of } \\
\text { People }\end{array}$ & 62 & 117 & 69 & 68 & 50 & 33 & 399 \\
\hline Percentage (\%) & 15.5 & 29.3 & 17.3 & 17.0 & 12.5 & 8.3 & 100.0 \\
\hline
\end{tabular}

As shown in table $8,37.8 \%$ students spend more than 3 hours online every day, and $8.3 \%$ spend more than 6 hours online every day, which is basically consistent with the survey that some students often surf the Internet overnight. If students do not spend a lot of time to take a break, it is impossible for them to have more than 6 hours of time online.

TABLE IX. SURVEY AND ANALYSIS ON THE SURFING THE INTERNET OVERNIGHT

\begin{tabular}{|c|c|c|c|c|c|}
\hline Index & Often & sometimes & occasionally & never & Total \\
\hline Number of People & 19 & 64 & 137 & 179 & 399 \\
\hline Percentage (\%) & 4.8 & 16.0 & 34.3 & 44.9 & 100.0 \\
\hline
\end{tabular}

As table 9 shows, there are not many overnight Internet surfers.

\section{E. The influence on eyesight for those who often use computer}

TABLE $X$. SURVEY ON THE INFLUENCE ON EYESIGHT

\begin{tabular}{|c|c|c|c|c|}
\hline Index & $\begin{array}{c}\text { Slightest decrease } \\
\text { but not obvious }\end{array}$ & $\begin{array}{c}\text { Significant } \\
\text { decrease }\end{array}$ & $\begin{array}{c}\text { No } \\
\text { decrease }\end{array}$ & Total \\
\hline $\begin{array}{c}\text { Number of } \\
\text { People }\end{array}$ & 187 & 145 & 67 & 399 \\
\hline $\begin{array}{c}\text { Percentage } \\
(\%)\end{array}$ & 46.9 & 36.3 & 16.8 & 100.0 \\
\hline
\end{tabular}

As is shown in table 10 , most of the students who use computers frequently suffer from vision loss.

\section{F. Survey on physical exercise}

Sports can not only promote the physical and mental health of college students, but also affect their outlook on life and values, and help them form the concept and habit of lifelong sports [6]. The participation in physical exercise is the factor that directly affects their physical health. To understand the situation of students' physical exercise is to find out the factors that affect students' physical health.

TABLE XI. SURVEY ON THE TIMES OF PHYSICAL EXERCISE EVERY WEEK

\begin{tabular}{|c|c|c|c|c|c|c|}
\hline Index & $\begin{array}{c}\text { No } \\
\text { exercise }\end{array}$ & $\begin{array}{c}1-2 \\
\text { Times }\end{array}$ & $\begin{array}{c}3 \\
\text { Times }\end{array}$ & $\begin{array}{c}4-5 \\
\text { Times }\end{array}$ & $\begin{array}{c}\text { Every } \\
\text { day }\end{array}$ & Total \\
\hline $\begin{array}{c}\text { Number of } \\
\text { People }\end{array}$ & 28 & 250 & 77 & 16 & 28 & 399 \\
\hline $\begin{array}{c}\text { Percentage } \\
(\%)\end{array}$ & 7.0 & 62.7 & 19.3 & 4.0 & 7.0 & 100.0 \\
\hline
\end{tabular}

As shown in table 11 , the frequency of weekly exercise is not very high with only 1-2 times for the most.

TABLE XII. SURVEY ON THE DURATION OF EACH EXERCISE

\begin{tabular}{|c|c|c|c|c|}
\hline Index & $\begin{array}{c}\text { Less than } 30 \\
\text { minutes }\end{array}$ & $\begin{array}{c}\text { Within 30 minutes } \\
\text { and } 1 \text { hour }\end{array}$ & $\begin{array}{c}\text { Over an } \\
\text { hour }\end{array}$ & Total \\
\hline $\begin{array}{c}\text { Number of } \\
\text { People }\end{array}$ & 140 & 201 & 58 & 399 \\
\hline $\begin{array}{c}\text { Percentage } \\
(\%)\end{array}$ & 35.1 & 50.4 & 14.5 & 100.0 \\
\hline
\end{tabular}

As shown in table 12, about half of the students exercise for 30-60 minutes each time, which is in the normal range. 35 percent of exercise time is less than 30 minutes, which does not work for our bodily health. It is also an unreasonable way to exercise for above 60 minutes, the proportion of which accounts for $14.5 \%$.

\section{G. The influence of sleep quality on physical health}

Sleep quality is the foundation of a healthy body. And a sound sleep can guarantee sufficient energy and healthy life. A survey on sleep duration and sleep quality is as follows.

TABLE XIII. SURVEY ON THE TIME OF SLEEP PER DAY

\begin{tabular}{|c|c|c|c|c|c|}
\hline Index & $\begin{array}{c}\text { Less than 6 } \\
\text { hours }\end{array}$ & $\begin{array}{c}6-7 \\
\text { hours }\end{array}$ & $\begin{array}{c}8-9 \\
\text { hours }\end{array}$ & $\begin{array}{c}\text { Above 10 } \\
\text { hours }\end{array}$ & Total \\
\hline $\begin{array}{c}\text { Number of } \\
\text { People }\end{array}$ & 59 & 250 & 86 & 4 & 399 \\
\hline Percentage (\%) & 14.8 & 62.7 & 21.6 & 1.0 & 100.0 \\
\hline
\end{tabular}

As shown in table $13,62.7 \%$ of students can guarantee their sleep time within the normal range. 14.8 percent of the students did not get enough sleep.

TABLE XIV. SURVEY ON SLEEP QUALITY

\begin{tabular}{|c|c|c|c|c|}
\hline Index & bad & general & good & Total \\
\hline Number of People & 57 & 235 & 107 & 399 \\
\hline Percentage (\%) & 14.3 & 58.9 & 26.8 & 100.0 \\
\hline
\end{tabular}

As shown in table $14,58.9 \%$ of students have average sleep quality, while $14.3 \%$ of college students have poor sleep quality. This has a big impact on their health. 


\section{H. The influence of smoking on physical health}

It is well known that smoking is one of the important factors affecting physical health. Therefore, it is necessary to investigate the smoking to obtain relevant data.

TABLE XV. SURVEY ON SMOKING

\begin{tabular}{|c|c|c|c|c|c|c|c|}
\hline Index & $\begin{array}{c}\text { Never } \\
\text { smoking }\end{array}$ & $\begin{array}{c}\text { Less than } 10 \text { cigarettes } \\
\text { every day }\end{array}$ & $\begin{array}{c}\begin{array}{c}\text { 10-19 cigarettes } \\
\text { every day }\end{array} \\
\end{array}$ & $\begin{array}{c}\text { More than } 20 \text { cigarettes } \\
\text { every day }\end{array}$ & $\begin{array}{l}\text { Quit smoking for } \\
\text { a year }\end{array}$ & $\begin{array}{c}\text { Quit smoking more } \\
\text { than } 2 \text { years }\end{array}$ & Total \\
\hline $\begin{array}{l}\text { Number of } \\
\text { People }\end{array}$ & 166 & 112 & 15 & ( & 96 & (1) & 399 \\
\hline $\begin{array}{l}\text { Percentage } \\
(\%)\end{array}$ & 41.6 & 28.1 & 3.8 & 2.0 & 24.1 & 0.5 & 100.0 \\
\hline
\end{tabular}

As shown in table 15, 41.6\% of students have never smoked, while $24.6 \%$ of college students have given up smoking. But some students still smoke.

\section{CONCLUSION AND SUGGESTION}

\section{A. Conclusion}

1. In terms of the physical changes of college students, after entering the university, their physical development continues and their height also increases year by year. Their weight shows a trend of decrease. BMI index is in the normal range. The figures of lung capacity, 50-meter dash and 1000-meter running decrease in a very significant way. As can be seen from the above analysis, the physical health of college students has been on the decline since their freshman year.

2. It is found from survey that college students spend a lot of time on the Internet. Long-term Internet activity has a negative impact on physical health, including eyesight and memory. It can be seen from the above that the main factors affecting the physical health of college students today also include bad network habits.

3. In the process of physical exercise, college students lack effective exercise time with very little amount of time for exercise. In addition, they lack exercise intensity. These are important factors affecting their physical health.

\section{B. Suggestion}

1. Through various channels, school, departments and sports departments should let students understand and realize the importance of physical health. It is beneficial for college students to establish the consciousness of lifelong physical education to emphasize the organic combination of college physical education and health education [1].
2. Schools must adopt the principle of combination "prevention" and "guidance" while paying attention to "study" and "exercise". Additionally, they should refuse to provide conditions for college students to indulge in the Internet in school management.

3. It should strengthen psychological counseling and guidance and ease the psychological pressure and psychological problems of college students. Therefore, it should organize more sports and recreational activities to enable college students to take part in more sports activities in their spare time [3].

\section{REFERENCE}

[1] Wu Na, Study on the Influence of Sport and Healthy Education in Institutions of High Learning on the Improvement of Physical Healthy Level of College Students [J] Teaching of Forestry Region, 2017(07)7980. (In Chinese)

[2] Deng Meng, Yang Ye, Analysis on the Educational Factors and Countermeasures of the Decrease of College Students' Physical Health [J] Contemporary Sports Technology, 2018,8(29),239-239+241. (In Chinese)

[3] Lan Bo, Analysis on the Factors and its Countermeasure of the Decline of College Students' Physical Health [J] Contemporary Sports Technology, 2018,8(29),239-239+241. (In Chinese)

[4] Yang Chunyan, Study on the Cause and Realistic Choice of "Physical Health Crisis" of College Students in China [J] Health Vocational Education, 2018,36(19),9-10. (In Chinese)

[5] Yang Chengwei, Tang Yan, Zhang He, Zhang Hong, Study on Effective Execution Path of Adolescent Physical Health Policy - From the Perspective of Perform System Model of Meter-Horn Policy [J].Sports Science, 2014(08) 56-63. (In Chinese)

[6] Shi Botao, Wang Yuqing, Zhang Mingrui, Huang Tianjia, Wang Lina, Analysis on Physical Exercise and Physical Health of College Students and its Countermeasure [J] Ability and Wisdom, 2018,09. 25. (In Chinese) 